\title{
Effect of Training-Detraining Phases of Multicomponent Exercises and BCAA Supplementation on Inflammatory Markers and Albumin Levels in Frail Older Persons
}

\author{
Adriana Caldo-Silva 1,2,*(D), Guilherme Eustáquio Furtado ${ }^{2,3, *}$, Matheus Uba Chupel ${ }^{2}$, André L. L. Bachi ${ }^{4,5}$ D,

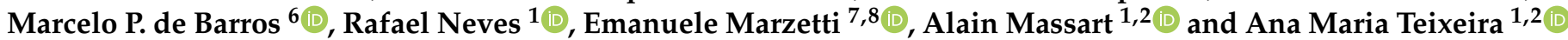

1 University of Coimbra, Faculty of Sports Sciences and Physical Education-(FCDEF-UC), 3040-248 Coimbra, Portugal; rsneves.prof@gmail.com (R.N.); alainmassart@fcdef.uc.pt (A.M.); ateixeira@fcdef.uc.pt (A.M.T.)

2 Research Centre for Sport and Physical Activity, CIDAF-FCDEF-UC, 3040-248 Coimbra, Portugal; matheusuba@hotmail.com

3 Health Sciences Research Unit: Nursing (UICISAE), Nursing School of Coimbra (ESEnfC), 3000-232 Coimbra, Portugal

4 Department of Otorhinolaryngology, ENT Lab, Federal University of São Paulo (UNIFESP), São Paulo 04025-002, Brazil; allbachi77@gmail.com

check for updates

Citation: Caldo-Silva, A.; Furtado, G.E.; Chupel, M.U.; Bachi, A.L.L.; de Barros, M.P.; Neves, R.; Marzetti, E.; Massart, A.; Teixeira, A.M. Effect of Training-Detraining Phases of Multicomponent Exercises and BCAA Supplementation on Inflammatory Markers and Albumin Levels in Frail Older Persons. Nutrients 2021, 13, 1106. https://doi.org/10.3390/ nu13041106

Academic Editors:

Christiano Capurso and

Catherine Féart

Received: 28 February 2021

Accepted: 21 March 2021

Published: 28 March 2021

Publisher's Note: MDPI stays neutral with regard to jurisdictional claims in published maps and institutional affiliations.

Copyright: (c) 2021 by the authors. Licensee MDPI, Basel, Switzerland. This article is an open access article distributed under the terms and conditions of the Creative Commons Attribution (CC BY) license (https:/ / creativecommons.org/licenses/by/ $4.0 /)$.
5 Post-Graduation Program in Health Sciences, Santo Amaro University (UNISA), São Paulo 04829-300, Brazil

6 Institute of Physical Activity Sciences and Sports (ICAFE), Interdisciplinary Program in Health Sciences, Cruzeiro do Sul University, São Paulo 01506-000, Brazil; marcelo.barros@cruzeirodosul.edu.br

7 Fondazione Policlinico Universitario “Agostino Gemelli” IRCCS, 00168 Rome, Italy; emanuele.marzetti@policlinicogemelli.it

8 Università Cattolica del Sacro Cuore, 00168 Rome, Italy

* Correspondence: dricaldo@gmail.com (A.C.-S.); guilhermefurtado@esenfc.pt (G.E.F.)

Abstract: Nowadays, it is accepted that the regular practice of exercise and branched-chain amino acids supplementation (BCAAs) can benefit the immune responses in older persons, prevent the occurrence of physical frailty (PF), cognitive decline, and aging-related comorbidities. However, the impact of their combination (as non-pharmacological interventions) in albumin and the inflammatory markers is not fully understood. Therefore, we investigated the effect of a 40 -week multifactorial intervention [MIP, multicomponent exercise (ME) associated or not with BCAAs] on plasma levels of inflammatory markers and albumin in frail older persons ( $\geq 75$ years old) living at residential care homes $(\mathrm{RCH})$. This study consisted of a prospective, naturalistic, controlled clinical trial with four arms of multifactorial and experimental (interventions-wahshout-interventions) design. The intervention groups were ME + BCAAs $(n=8)$, ME $(n=7)$, BCAAs $(n=7)$, and control group $(n=13)$. Lower limb muscle-strength, cognitive profile, and PF tests were concomitantly evaluated with plasma levels of albumin, anti- and pro-inflammatory cytokines [Interleukin-10 (IL-10) and Tumor Necrosis Factor-alpha (TNF- $\alpha$ ) respectively], TNF- $\alpha /$ IL-10 ratio, and myeloperoxidase (MPO) activity at four different time-points: Baseline (T1), after 16 weeks of multifactorial intervention (T2), then after a subsequent 8 weeks washout period (T3) and finally, after an additional 16 weeks of multifactorial intervention (T4). Improvement of cognitive profile and muscle strength-related albumin levels, as well as reduction in the TNF- $\alpha$ levels were found particularly in ME plus BCAAs group. No significant variations were observed over time for TNF- $\alpha / \mathrm{IL}-10$ ratio or MPO activity. Overall, the study showed that MIP triggered slight alterations in the inflammatory and physical function of the frail older participants, which could provide independence and higher quality of life for this population.

Keywords: inflammaging; cognitive impairment; cytokines; protein intake; physical frailty 


\section{Introduction}

Aging is characterized as a natural degenerative process strongly linked to diminished immune efficiency, and also to enhanced inflammatory responses, and thus, to higher risks of infections in older persons [1]. The sedentary lifestyle, per se, is one of the most important contributors to age-related illness, whereas regular physical exercises (rPE)—based on hormesis principles—could chronically slow down the aging immune/inflammatory dysfunctions [2]. In this sense, reduction of systemic levels of interleukin-10 (IL-10), a classical anti-inflammatory cytokine, with elevation on Tumor Necrosis Factor-alpha (TNF- $\alpha$ ) levels are associated with aging [3]. Although the participation in rPE programs does not stop the progression of aging [4], staying in moderate rPE programs can help making the aging process more rewarding, with lower incidence of premature chronic diseases [5]. In addition to the comorbidities outcomes, both aging and the sedentary behavior may speed up the loss of mobility and functional autonomy [6], reducing the quality of life [7], and also increasing the susceptibility to physical frailty (PF) and cognitive decline [8].

The age-related PF syndrome is defined by loss of muscle mass (and sarcopenia), by low physical activity levels, and often accompanied by low protein intake [9]. Cognitive decline, in turn, is characterized by confusion and progressive loss of memory and neuromotor skills [10]. However, these two outcomes reveal biological and phenotypic similarities, which is the reason leading to the current scientific interest in investigating populations affected by these disorders [11]. In this sense, $\mathrm{rPE}$ could also provide protection against both PF and cognitive decline in very old people [12], with most of these benefits related, at least in part, to changes that occur in the immune system [13]. Recent findings have shown that multicomponent exercise (ME) interventions, those that include different types of endurance, muscle strength, and balance exercises in the same session, appear to have a superior effect on cognitively and physically frail older persons [14,15].

Participation of older persons in rPE ameliorates not only antigen recognition, but also immune responsiveness in general, as some evidence has shown that increased levels of physical activity using exercise routines can even extend the protection provided by the influenza vaccine in older persons [16], as well as a regulation of systemic inflammatory status [17]. Apart from the modulating effects of rPE, nutritional habits also play an important role in determining immune and inflammatory efficiency, especially in older persons [2]. In fact, malnutrition in older population is a serious concern for health systems around the world, since it increases the risk of comorbidities occurrence with subsequent higher health care costs $[7,8]$. Indeed, nutritional supplementation with vitamins, antioxidants, and protein components (including isolated amino acids) have already demonstrated positive results against PF, cognitive impairment, sarcopenia and other age-related disorders [18].

Supplementation with BCAA, in the absence of branched-chain aminotransferase (BCAT) activity in the liver implies that a dietary supply of BCCAs would ensure an almost intact passage through the liver directly to the muscle tissue, which seems to be advantagous to restrain sarcopenia and frailty [19]. Supplementation with BCAA, especially in association with regular exercises, was demonstrated to improve muscle strength and cognitive functions in the older population, which are safe and low-cost strategies to circumvent the general limitations imposed by the aging process [20-22].

Among several pro/anti-inflammatory biomarkers used in the context of exercise and nutrition sciences [23], myeloperoxidase (MPO) stands out as a valid marker largely released by activated neutrophils, with potent pro-oxidative/pro-inflammatory actions 24 [24]. MPO activity also appears as a biomarker that was strongly associated with frailty and risk of mortality in a study conducted in a large community-dwelling frail octogenarians and nonagenarians [25]. Recently, a similar intervention demonstrated the slight reduction of serum MPO activity triggered by the combination of Taurine and ME in older persons [26]. Instead, albumin concentrations are currently used for the assessment of the nutritional status of an individual, and low albumin concentrations have been associated with increased mortality after correlation for age, body mass index (BMI), gender, and several chronic comorbidities [27]. In this sense, multifatorial interventions programs 
(MIP, exercise plus protein suplmentattion) that target to maintain (or even increase) albuminemia in older persons could characterize an important strategy to diminish the harmful effects of aging and its comorbidities [28].

Therefore, the aim of this work was to evaluate the effect of a 40-week MIPon plasma/serum pro- and anti-inflammatory markers of the immune system in older persons living in residential care homes $(\mathrm{RCH})$. Furthermore, we hypothesized that ME plus BCAAs may have an impact on the systemic albumin levels, inflammatory variables, cognitive profile, and physical function of the participants.

\section{Materials and Methods}

\subsection{Preliminary Procedures and Ethics}

This is a prospective, naturalistic, controlled clinical trial (treatment vs care). All subjects volunteered to participate in the exercise classes or the supplementation programs. Consent forms were signed by the institution's directors, the participants and their legal representatives before testing and intervention. This study was approved by the Ethical Committee of Faculty of Sport Sciences and Physical Education, University of Coimbra (reference number: CE/FCDEFUC/00282018), respecting the Portuguese Resolution (Art. ${ }^{\circ} 4$ th; Law no. 12/2005, 1st series) on ethics in human research and the Helsinki's Declaration. This study was properly registered with clinicaltrials.gov register NCT04376463.

\subsection{Participants Elegibility}

Study participants were selected through a non-probabilistic trial (plus controlled sampling) living in public and private $\mathrm{RCH}$. The eligible criteria for the participants in this study were, at the time of first screening: (i) Participants had to be 70 years old or more; (ii) physically frail and pre-frail; (iii) clinically stable with their drug therapy updated; (iv) being able to perform the Time Up and Go test in $\leq 50 \mathrm{~s}$ that indicate severe mobility independence [29]; (v) not participating in other structured rPE; (vi) not presenting any type of health condition or use medication that might prevent the functional self-sufficiency test performance or attention impairment (such as severe cardiopathy, hypertension, uncontrolled asthmatic bronchitis or severe musculoskeletal conditions); (vii) not presenting mental disorders or hearing/visual impairment that could prevent the evaluations and activities proposed, according to the institutional medical staff; (viii) not presenting morbid obesity (BMI $\geq 40$ ). At the end of the recruitment process, 80 older persons entered the enrollment phase.

\subsection{Participants Allocation}

All the participants were selected through a non-probabilistic trial (plus controlled sampling) based on the geographical area of Coimbra, Portugal, living in public and private residential care homes (RCH) or frequenting day centres in the local community. From the 80 participants initially screened, 50 eligible participants were allocated in their respective intervention groups. However, for the specific reasons highlighted in Figure 1, only 35 participants (age $=83 \pm 3$ years-old) completed the 40 weeks multifactorial intervention, divided in the following groups: $\mathrm{ME}(n=7), \mathrm{ME}+\mathrm{BCAA}(n=8), \mathrm{BCAA}(n=7)$, and the no-regular exercise/no-supplementation control group $(C G, n=13)$. All the procedures were performed according to the Consolidated Standards of Reporting Trials (CONSORT) guidelines [30]. 


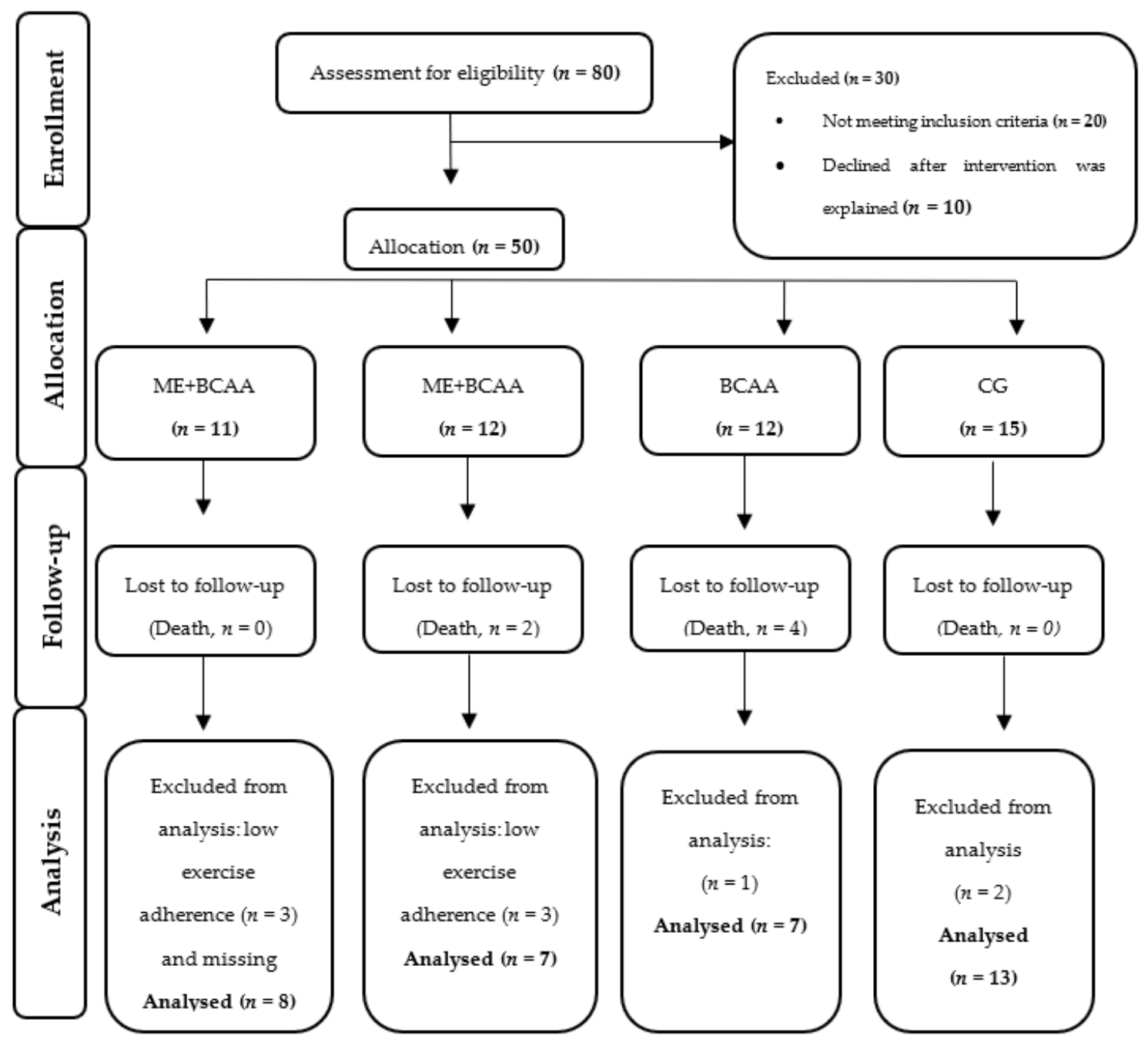

Figure 1. CONSORT Flowchart of study participants [30]. ME + BCAA, Multicomponent Exercise + Branched Chain Amino Acid; ME, Multicomponent Exercise; BCAA, Branched Chain Amino Acid; CG, Control Group.

\subsection{Experimental Design}

This study is a four-phase prospective, naturalistic, controlled clinical trial with four arms of MIP experimental design (ME + BCAAs, BCAAs, ME, and CG). In the first phase, a baseline data collection (T1) was done followed by 16 weeks of MIP. The second phase consisted of a second data collection (T2) followed by an 8 week washout phase. Phase 3 consisted of a third data collection, followed by the resumption of the MIP for a period of 16 weeks. The last data collection took place after the 16 weeks of intervention (T4) (Figure 2).

\section{Outcome Measures}

All the assessments were performed in the morning, between 10 and 11:45 a.m. One session was used to apply a short test battery to measure biosocial, global health status, cognition profile, nutritional, physical, and physical frailty status. In the second consecutive day, blood samples were collected and stored at $-80^{\circ} \mathrm{C}$ until further analysis. 


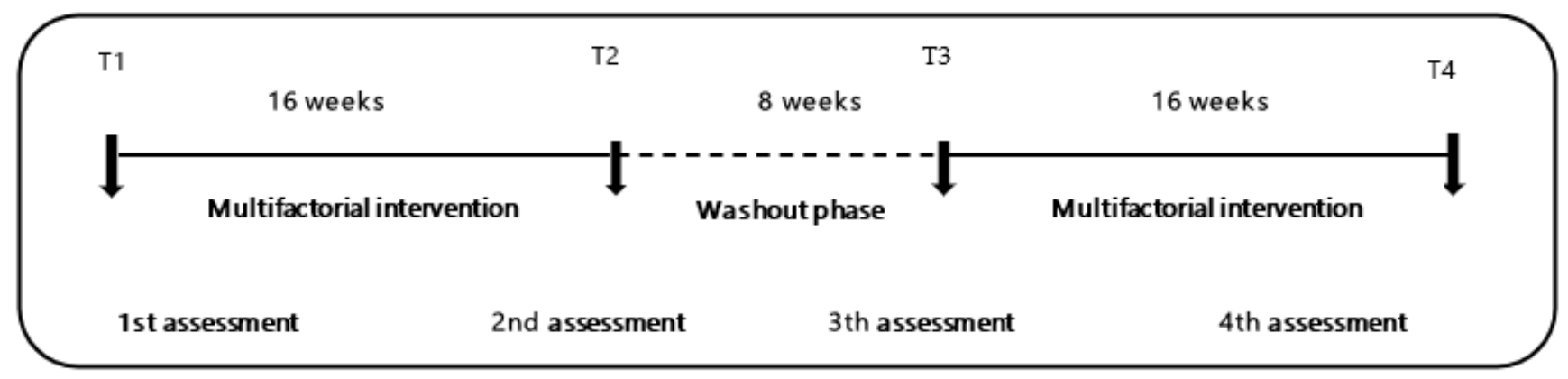

Figure 2. Chronological order of multifactorial interventions study design. T1 to T2 (elastic-band exercise, 16 weeks, 8 weeks), T2 to T3 (wash-out), T3 to T4 (multicomponent exercise, 16 weeks).

\subsection{Physical Frailty Index}

The phenotype of Fried's physical frailty index was used [9]. Weight loss was assessed by a self-report of unintentional weight loss of $4 \mathrm{~kg}$ or more in the last 6 months. Selfreported exhaustion was evaluated by a negative concordance of question number 7 and 20 of the Center of Epidemiologic Studies for Depression scale [31]. Hand-grip strength was assessed in kilograms by a hand-held (HGT) dynamometer (Lafayette 78,010, Sagamore, United States). The best result of the two trials was used for scoring purposes. Participants who were unable to perform the HGT and those in the lowest $20 \%$ were categorized as positive [32]. The cutoff reference values for HGT of $\geq 29 \mathrm{~kg}$ for male and $\geq 17 \mathrm{~kg}$ for female were adopted. Slowness was measured by the " 15 feet $(4.6 \mathrm{~m})$ walking test". Based on the cutoff values of Fried's study population, the times of $\geq 7 \mathrm{~s}$ for males and $\geq 6 \mathrm{~s}$ for females were adopted for positive scores of slowness. The best time of the two trials was used for the final scoring. Low physical activity (PA) levels were assessed by the International PA Questionnaire short version (IPAQ-SV) [33]. There are three levels of PA suggested for classification: Inactive, minimally active, and highly active. Participants classified as inactive had a positive score for this PF component. A positive evaluation in one or two criteria classified the participants as pre-frail, in three or more criteria as frail, and as non-frail when the subject scored none of the five PF indicators. The prevalence of PF was calculated to generate a frailty total score, as well as the presence of each of the five criteria of the Fried's model ( 0 to 5 points). In this study, participants classified as frail ( 3 or more points) and pre-frail ( 2 points) were included.

\subsection{Nutritional Assessment}

Daily diet at the $\mathrm{RCH}$ was prescribed by a registered nutritionist and was provided for all the participants without any change or interference of the research staff. On the basis of the information provided, the diet was analyzed using specific tools (photographic quantification of portions, food table) for the Portuguese population [34-36]. Due to the relationship between the frailty status and severe decrease of muscle mass (or sarcopenia) which had already been demonstrated in several studies, the objective of this nutritional assessment was to characterize the protein consumption of the participants. In addition, the Mini Nutritional Assessment (MNA) questionnaire was applied [37,38]. This consists of 18 questions that present a maximum score of 30 points, and classifies the participants as malnourished ( $\leq 17$ points), at risk of malnutrition ( $17<\mathrm{MNA}<23.5$ points), and as having a normal nutritional status (MNA $>23.5$ points).

\subsection{Lower Limb Muscle-Strength Test}

The Five-Times-Sit-to-Stand-Test (5TSS test) was applied. This test assesses the functional strength of the lower limbs, transition movements, balance, and risk of falling. The participant is instructed to stand as quickly as possible five times, without stopping in the middle. In addition, the participant should be encouraged to keep his arms crossed over his chest. The instructor must count the time with a stopwatch and must count each 
position out loud so that the participant remains oriented. The test is stopped when the participant reaches the orthostatic position at the 5th repetition [29].

\subsection{Clinical and Health Status}

The Charlson comorbidity index (CCI) was calculated based on the registry of individual comorbidities combined with age and gender, to account for a final score [39]. The anthropometric assessment included body mass $(\mathrm{kg})$ and stature $(\mathrm{m})$. Body mass was determined using a portable scale (Seca ${ }^{\circledR}$, model 770 ,Berlin, Germany) with a precision of $0.1 \mathrm{~kg}$, whereas stature was determined using a portable stadiometer (Seca Body meter ${ }^{\circledR}$, model 208, Berlin, Germany) with a precision of $0.1 \mathrm{~cm}$. Body mass index (BMI) was calculated according to the formula (BMI = body mass $/$ stature $^{2}$ ). The standardized procedures described in previous studies were followed [40].

\subsection{Cognitive Profile}

The Portuguese version of the Mini Mental State Examination (MMSE) was used [41]. The MMSE is a 30-point scale instrument that evaluates five domains of cognition: Orientation, immediate recall, attention and calculation, delayed recall, and language. This scale classifies individuals by progressive cognitive skills: (0-9 points) severe cognitive impairment; (10-18 points) moderate cognitive impairment; (19-24 points) mild cognitive impairment; and (25-30 points) normal cognitive profile [42].

\subsection{Biochemical Analysis}

Non-fasting blood collection was done in the morning (between 10:00 a.m. and 11:00 a.m.). Blood samples were collected by venipuncture, after $15 \mathrm{~min}$ of individual rest in an isolated and quiet room, at the four time-points of the study assessment. The participants were asked to avoid alcohol and caffeine intake on the previous day of blood collection, and also to maintain their sleep habits during the previous night. After centrifugation at $3000 \mathrm{rpm}$ at $4{ }^{\circ} \mathrm{C}$ during $15 \mathrm{~min}$, plasma and serum samples were aliquoted into Eppendorf tubes and stored at $-80{ }^{\circ} \mathrm{C}$ until used for the determination of interleukin-10 (IL-10), tumour necrosis factor alpha (TNF- $\alpha$ ), myeloperoxidase activity (MPO), and total albumin concentrations. The ELISA (Thermo Fisher, Gloucester, UK) intra-assay coefficients of variability were $4.1 \%$ for IL- 10 and $3.0 \%$ for TNF- $\alpha$.

\subsection{Full Characterization of the MIP \\ 3.7.1. Oral BCAAs}

The BCAAs power mixture was composed of L-leucine (Leu), L-isoleucine (Ile), and L-valine (Val) in the proportion of 2:1:1 (MyProtein ${ }^{\circledR}$, Cheshire, UK), accounting for $20 \mathrm{kcal}$ per portion, comprising 5 grams (g) of supplement: $1.85 \mathrm{~g} \mathrm{Leu}, 0.93 \mathrm{~g}$ Ile, and $0.93 \mathrm{~g}$ Val. The unflavored supplement was used as to not induce ingestion preferences for specific flavors. The BCCAs were diluted in $200 \mathrm{~mL}$ of water and given immediately after the exercise sessions to the participants in the ME + BCAAs and BCAAs groups [43]. The supplement dose was fixed at $0.21 \mathrm{~g}$ total BCAAs $/ \mathrm{kg} /$ session, with individual portion sachets, administered in the morning, between 09:00 and 11:30 a.m. [44]. We opted to exclude maltodextrin or the carnosine-based placebo here, since the carbohydrate ingestion could mask the effort perception and cognitive indexes in our older persons volunteers, compared to the amino acid supplementation [45]. In addtion, carnosine, as well as other $\beta$-alanine derivatives, were shown to affect cognitive functions, including the perception of wellness, mood, and depression indexes [46]. Therefore, we decided to split BCAA-supplemented (ME + BCAAs and BCAAs) and BCAAs-absent groups (ME and CG) according to the proximity between the residential care homes $(\mathrm{RCH})$, where the ME programs were effectively applied. No communication was reported between volunteers from the BCAA-supplemented and no-BCAA supplemented groups in our study. 


\subsubsection{Washout Period (Oral BCAAs)}

In this phase, the participants endured a cessation period of 8 weeks, when supplementation of the ME + BCAAs and BCAAs groups was suspended in order to verify whether the supposed benefits of BCAAs were maintained or lost [21].

\subsubsection{Exercise Intervention (Phase 1)}

The exercise program was divided in two interventions of 16 weeks each, separated by an 8-week detraining (washout) period. Exercise sessions were offered twice a week, with an interval of $36 \mathrm{~h}$ for adequate physiological recovery and rest. The exercise protocol respected the guidelines of exercise prescription for older persons and the guidelines of exercise periodization by the American College of Sports Medicine (ACSM) [47,48]. The program started with an adaptation period of 2 weeks, in which seven different exercises were performed using elastic bands (TheraBand ${ }^{\circledR}$, Hygenic Corporation, Akron, OH, USA). The participants were closely supervised for two initial sessions aiming for equipment familiarization and adjustments to the Rating Perceived Exertion (RPE OMNI) scale [49]. During these familiarization sessions, the participants learned the correct technique of the exercises, and selected the proper color, length, and grip width of the elastic bands. The exercise intensity was indirectly calculated using the Karvonen's formula to predict the target heart rate (HR), with $\mathrm{HR}_{\max }$ being calculated by an adjusted formula for older persons [50].

$$
\mathrm{HR}=\left(\left(\mathrm{HR}_{\max }-\text { resting } \mathrm{HR}\right) \times \% \text { Intensity }\right)+\text { resting } \mathrm{HR}
$$

After the adaptation period, the exercise program was progressively intensified by increments in both the number of exercises (from 8 to 10 exercises during the rest of the exercise intervention) and the proposed physical effort, imposed by different intensity color bands, according to the OMNI table [49]. The elastic-band exercises applied in the Phase 1 period are shown in Table 1. For safety reasons, the exercise programs were also monitored using heart rate monitors (Polar M200; Polar Electro Oy, Kempele, Finland). Additionally, intensity was measured through the specific rating perceived exertion (RPE) scales for each exercise program [51]. The RPE used is an arbitrary scale ranging from 0 to 10 points, with identical intervals and with reference to the quality of effort: (0) Nothing at all; (1) very weak; (2) weak; (3) moderate; (4) somewhat strong; (5-6) strong; (7-9) very strong; (10) very, very strong (almost maximal).

Table 1. Example of elastic-band exercise sessions applied in phase 1.

\begin{tabular}{|c|c|c|c|c|c|c|c|}
\hline Warm-Up & & & $5 \mathrm{~min}$ & PSE 1-3 & Progression & Weeks & Intensity (Color) \\
\hline Exercises (8-10) & Sets & Repetitions Cadence & Interval & PSE & $2 \times 10$ & 2 & Yellow \\
\hline Front squat & $2-3$ & $10-20 \quad 2: 3$ & $30-45 s$ & 4 to 6 & $3 \times 20$ & 2 & Yellow \\
\hline Chair unilateral hip flexion & $2-3$ & $10-20$ & $30-45 s$ & 4 to 6 & $3 \times 10$ & 2 & Red \\
\hline Chair Bench over row (with flexion) & $2-3$ & $10-20$ & $30-45 s$ & 4 to 6 & $3 \times 20$ & 2 & Red \\
\hline Chest Press (stand and/or chair) & $2-3$ & $10-20$ & $30-45 s$ & 4 to 6 & $3 \times 10$ & 2 & Green \\
\hline Standing (or chair) reverse fly & $2-3$ & $10-20$ & $30-45 s$ & 4 to 6 & $3 \times 20$ & 2 & Green \\
\hline Shoulder Press/twist arm position & $2-3$ & $10-20$ & $30-45 s$ & 4 to 6 & $3 \times 15$ & 2 & Blue \\
\hline Chair (or stand) frontal total raiser & $2-3$ & $10-20$ & $30-45 s$ & 4 to 6 & $3-4 \times 10^{-15}$ & 2 & Blue \\
\hline Biceps arm curl (stand and/or chair) & $2-3$ & $10-20$ & $30-45 s$ & 4 to 6 & & & \\
\hline Chair Overhead triceps extension & $2-3$ & $10-20$ & $30-45 s$ & 4 to 6 & & & \\
\hline Cooling down & & & $5 \mathrm{~min}$ & PSE $1-2$ & & & \\
\hline
\end{tabular}

Notes: PSE-Perception subjective effort.

\subsubsection{Washout (ME Detraining)}

In this phase, the participants endured a detraining period of 8 weeks, when the ME programs were suspended. The aim was to check if the physiological adaptations acquired during the first phase of ME were maintained or if an 8-week interruption was able to revert the possible effects on immune changes [52]. 


\subsubsection{Exercise Retraining Protocol}

The phase 3 (exercise retraining) protocol was also based on the resistant TheraBand (TheraBand ${ }^{\circledR}$, Hygenic Corporation, Akron, OH, USA) elastic bands (Table 2), but included walking, steps, and balance exercises (sometimes with dumbbells and ankle/wrist weights) to compose a multicomponent exercise program for an identical 16-week period (twice a week, on alternate days, also totalizing 32 sessions). The multicomponent program (Table 2) was described by Furtado et al. [53]. The phase 3 program aimed to reproduce most of the daily activities of the older persons in this study [54].

Table 2. Example of multicomponent exercise sessions applied in phase 2.

\begin{tabular}{|c|c|c|c|c|c|}
\hline Exercises (8-10) & Sets & Repetitions & Cadence & Interval & PSE \\
\hline Front squat & $2-3$ & $10-20$ & $2: 3$ & $30-45 s$ & 4 to 6 \\
\hline Chair unilateral hip flexion & $2-3$ & $10-20$ & $2: 3$ & $30-45 s$ & 4 to 6 \\
\hline Chair Bench over row (with flexion) & $2-3$ & $10-20$ & $2: 3$ & $30-45 s$ & 4 to 6 \\
\hline Chest Press (stand and/or chair) & $2-3$ & $10-20$ & $2: 3$ & $30-45 s$ & 4 to 6 \\
\hline Standing (or chair) reverse fly & $2-3$ & $10-20$ & $2: 3$ & $30-45 s$ & 4 to 6 \\
\hline Shoulder Press/twist arm front position & $2-3$ & $10-20$ & $2: 3$ & $30-45 s$ & 4 to 6 \\
\hline Chair (or stand) frontal total raiser & $2-3$ & $10-20$ & $2: 3$ & $30-45 s$ & 4 to 6 \\
\hline Biceps arm curl (stand and/or chair) & $2-3$ & $10-20$ & $2: 3$ & $30-45 s$ & 4 to 6 \\
\hline $\begin{array}{c}\text { Chair Overhead triceps extension } \\
\text { Circuit Training }\end{array}$ & $2-3$ & $10-20$ & $2: 3$ & $30-45 \mathrm{~s}$ & 4 to 6 \\
\hline Walking around the room & $2-3$ & $3 \mathrm{~min}$ & & $30-45 s$ & 4 to 6 \\
\hline Balance/agility exercise & $2-3$ & $3 \mathrm{~min}$ & & $30-45 s$ & 4 to 6 \\
\hline
\end{tabular}

Notes: PSE-Perception subjective effort.

\subsection{Statistical Analysis}

The descriptive statistics for each group, at the baseline and follow-up evaluations, were reported as the mean plus standard deviation $(M \pm S D)$, except when mentioned otherwise. All the variables were checked for the normally residual distribution and values were logarithmically transformed when appropriate. One-way Analysis of Variance ANOVA was used to determine baseline differences between the four groups in all the parameters. Effects of time, group, and time $x$ group interactions were assessed through repeated measures ANOVA and Bonferroni post-hoc for multiple comparisons. Additionally, univariate analysis was performed using the paired $t$-test for comparisons during the first phase of interventions (T1 vs. T2). All statistical analyses were performed using the SPSS 21 (SPSS Inc., Chicago, IL, USA), and the level of significance was set at $p<0.05$.

\section{Results}

The dynamics of the MIP groups and drop-outs are presented in detail in Figure 1. From the $50(100 \%)$ participants initially selected, only 35 participants $(70 \%)$ completed the intervention. This is an expected experimental loss, as reported by several previous studies [55]. None of the dropouts left the intervention due to injuries or adverse responses. Reported deaths were due to acute events triggered by chronic clinical conditions. Table 3 shows the characterization of participants by MIP groups at the baseline, including nutritional, cognitive, frailty, anthropometric, and body composition status. No statistically significant differences in all the variables appeared, expect for time in residential care and nutritional status assessed by MNA $(p<0.05)$. However, all the groups were within the well-nourished category. 
Table 3. Characterization of participants by intervention groups at baseline.

\begin{tabular}{|c|c|c|c|c|c|}
\hline Variables & $\begin{array}{c}\mathrm{ME}+\text { BCAA } \\
(n=8)\end{array}$ & $\begin{array}{c}\text { ME } \\
(n=7)\end{array}$ & $\begin{array}{l}\text { BCAA } \\
(n=7)\end{array}$ & $\begin{array}{c}\text { CG } \\
(n=13)\end{array}$ & \multirow[t]{2}{*}{$p$-Value } \\
\hline & $\mathbf{M} \pm \mathbf{S D}$ & $\mathbf{M} \pm \mathbf{S D}$ & $\mathbf{M} \pm \mathbf{S D}$ & $\mathbf{M} \pm \mathbf{S D}$ & \\
\hline Age (years) & $80 \pm 6.1$ & $86.7 \pm 4$ & $84.2 \pm 5.8$ & $83.1 \pm 5.4$ & 0.139 \\
\hline Time in residential care (years) & $3.6 \pm 1$ & $4.7 \pm 1.4$ & $4.5 \pm 1.1$ & $5 \pm 1$ & 0.06 \\
\hline MNA (0-30 pts) & $25.5 \pm 2.2$ & $24 \pm 2.7$ & $21.7 \pm 2.8$ & $24.7 \pm 1.8$ & 0.02 \\
\hline BMI $\left(\mathrm{kg} / \mathrm{m}^{2}\right)$ & $28.53 \pm 5.1$ & $28.7 \pm 5.6$ & $25.8 \pm 3.1$ & $30.2 \pm 3.7$ & 0.23 \\
\hline Stature $(\mathrm{cm})$ & $158 \pm 0.05$ & $150 \pm 0.06$ & $161 \pm 0.12$ & $155 \pm 011$ & 0.16 \\
\hline Comorbidity index (0-10 pts) & $4.87 \pm 1.12$ & $5.28 \pm 0.95$ & $5.42 \pm 1.1$ & $4.92 \pm 1.2$ & 0.71 \\
\hline Schooling time (years) & $4 \pm 0$ & $4 \pm 0$ & $4 \pm 0$ & $4 \pm 0$ & 0.99 \\
\hline Cognitive profile (0-30 pts) & $26.00(3.11)$ & $21.00(3.78)$ & $20.85(2.79)$ & $21.69(2.89)$ & 0.00 \\
\hline Physical Frailty index (0-5 pts) & $2.00(0.53)$ & $2.71(1.1)$ & $3.00(0.57)$ & $2.16(0.71)$ & 0.40 \\
\hline Daily Individual Protein ( $\mathrm{gr} / \mathrm{kg} /$ day) & $1.42 \pm 0.28$ & $1.83 \pm 0.44$ & $1.48 \pm 0.22$ & $1.60 \pm 0.23$ & 0.159 \\
\hline BCAAs (per person/gr/week) & $30.3 \pm 6.0$ & n.d. & $28.4 \pm 5.0$ & n.d. & \\
\hline
\end{tabular}

Notes: BMI: Body mass index; MNA: Mini nutritional assessment; $\mathrm{M} \pm \mathrm{SD}$ : Mean (standard and deviation); pts: Points; Kg/m²: Kilograms; $\mathrm{cm}$ : Centimeters; One-way ANOVA was used to compare groups, except for the Comorbidity index (Fisher Exact Test). BCAA Branched Chain Amino Acids.

\subsection{Biochemical Analysis}

Table 4 shows the results for IL-10, TNF- $\alpha$ and TNF- $\alpha /$ IL-10 ratio, MPO, albumin, 5TSS-Test, as well as Fried (score) and MMSE. Concerning the IL-10 levels, a classical antiinflammatory cytokine, not only no effects of time $(p=0.690)$ or time vs. experimental groups were found (CG, BCAAs, ME, and ME + BCAAs), F(degrees of freedom-df:9, 51) = 1.567, $p=150$ ), but also Bonferroni post-hoc comparisons did not result in significant variations between time vs. groups $(p>0.05)$. Regarding the TNF- $\alpha$ levels, although we did not observe any interference of time on these pro-inflammatory cytokine levels $(p>0.05$, Table 4 , repeated ANOVA analyses revealed significant interactions between time vs. groups: $\mathrm{F}(\mathrm{df}: 6.758,47.303$ ) $=2.524, p=0.029$. In addition, Bonferroni post-hoc comparisons showed not only higher TNF- $\alpha$ values in the ME + BCAAs group between T2 and T3 $(p=0.01)$, but also a significant decrease of TNF- $\alpha$ was observed between T3 and T4 within the same experimental group (ME + BCAAs, $p<0.01)$. The TNF- $\alpha$ values were unchanged in all other experimental groups. Regarding the TNF- $\alpha /$ IL-10 ratios, no significant variations were observed over time $(p=0.703)$ or within the interactions (time vs. group, $p=0.638$ ).

Concerning MPO activity, Table 4 shows that this biomarker was not influenced by time (T1, T2, T3, and T4), except for a slight tendency regarding interactions (time vs. group): $\mathrm{F}(\mathrm{df}: 9,48)=2.010, p=0.059$. Particularly, the Bonferroni post-hoc comparisons showed that the BCAAs group presented higher MPO activity after re-supplementation (T4) than the values found in the T2 time-point (after the first 16 weeks of the supplementation period, $p=0.026$ ). No significant alterations in the MPO activity were observed in other comparisons between groups.

In terms of serum albumin (Table 4), a statistically significant difference in the effect of time was found ( $\mathrm{F}(\mathrm{df}: 1949 ; 46,784)=3.841, p=0.02)$, but no other (time vs. group) significant difference was detected between the albumin levels $(p=0.219)$. The pairwise comparison using Bonferroni post-hoc showed a decrease of albumin levels in the BCAAs group in the T3 time-point (after the washout period, $p=0.04$ ) as compared to the values found in $\mathrm{T} 1$, whereas no other significant variations were observed in the other groups $(p>0.05)$.

\subsection{Five-Times-Sit-to-Stand-Test (5TSS test)}

Table 4 shows no effect of time ( $p=0.841$ ) or interactions (time vs. group, $p=0.846$ ) on the time elapsed to perform the 5TSS test. However, post-hoc adjustments showed that the ME + BCAAs and BCAAs groups presented a significant reduction of the time elapsed to perform this test at time-points T2, T3, and T4 $(p=0.009, p=0.014$, and $p=0.024$, respectively). 
Table 4. Statistical analysis comparison of four time-points moments of multifactorial intervention for biochemical, cognitive profile, physical frailty index, and functional fitness test.

\begin{tabular}{|c|c|c|c|c|c|c|c|c|}
\hline \multirow[b]{2}{*}{ Biomarker/Variables } & \multirow[b]{2}{*}{ Groups } & \multicolumn{4}{|c|}{ Time-Points of Evaluation } & \multirow{2}{*}{ Effect } & \multirow{2}{*}{$\mathbf{F}$} & \multirow{2}{*}{ Overall $p$} \\
\hline & & T1 & T2 & T3 & T4 & & & \\
\hline & & $\mathbf{M} \pm \mathbf{S D}$ & $\mathbf{M} \pm \mathbf{S D}$ & $\mathbf{M} \pm \mathbf{S D}$ & $\mathbf{M} \pm \mathbf{S D}$ & & & \\
\hline & $\mathrm{ME}+\mathrm{BCAA}$ & $10.36(6.96)$ & $12.0(6.53)$ & $15.99(7.98)$ & $11.52(7.56)$ & & & \\
\hline IL-10 & ME & $8.68(7.68)$ & $12.25(12.35)$ & $4.16(3.39)$ & $10.53(5.82)$ & Time & 0.491 & 0.690 \\
\hline \multirow[t]{3}{*}{$(\mu \mathrm{g} / \mathrm{mL})$} & BCAA & $7.71(2.54)$ & $9.24(4.15)$ & $13.83(6.94)$ & $9.85(10.89)$ & Time ${ }^{*}$ group & 1.567 & 0.150 \\
\hline & CG & $16.10(7.4)$ & $12.21(2.81)$ & $12.74(7.36)$ & $20.45(5.42)$ & & & \\
\hline & $\mathrm{ME}+\mathrm{BCAA}$ & $62.44(53.65)$ & $71.42(38.06)$ & $112.86(62.51)$ & $57.37(31.18)$ & & & \\
\hline TNF- $\alpha$ & ME & $41.78(54.08)$ & $45.83(21.07)$ & $24.92(15.60)$ & $54.05(29.19)$ & Time & 1.552 & 0.210 \\
\hline \multirow[t]{2}{*}{$(\mathrm{pg} / \mathrm{mL})$} & BCAA & $32.65(15.74)$ & $37.18(26.91)$ & $62.93(35.77)$ & $60.02(55.42)$ & Time* group & 2.524 & 0.015 \\
\hline & CG & $44.46(41.72)$ & $44.81(37.16)$ & $41.78(37.86)$ & $57.01(44.15)$ & & & \\
\hline \multirow{5}{*}{$\begin{array}{c}\text { TNF- } \alpha / \mathrm{IL}-10 \\
\text { ratio } \\
(\mathrm{pg} / \mathrm{mL})\end{array}$} & $\mathrm{ME}+\mathrm{BCAA}$ & $6.24(4.46)$ & $7.47(4.09)$ & $6.96(1.63)$ & $6.10(3.25)$ & & & \\
\hline & ME & 4.43 (1.99) & $9.06(10.46)$ & $8.64(7.36)$ & $5.70(3.27)$ & Time & 0.472 & 0.703 \\
\hline & BCAA & $5.44(3.39)$ & $3.85(1.84)$ & $5.45(1.54)$ & $11.19(9.77)$ & Time ${ }^{*}$ group & 0.777 & 0.638 \\
\hline & CG & $4.10(1.27)$ & $5.37(1.56)$ & $4.56(1.80)$ & $4.41(0.38)$ & & & \\
\hline & $\mathrm{ME}+\mathrm{BCAA}$ & $\begin{array}{c}5653.91 \\
(1106.71)\end{array}$ & $\begin{array}{c}5871.97 \\
(1159.09)\end{array}$ & $\begin{array}{c}4843.50 \\
(1221.63)\end{array}$ & $\begin{array}{l}5196.53 \\
(591.62)\end{array}$ & & & \\
\hline \multirow{3}{*}{$\begin{array}{c}\text { MPO } \\
(\mu \mathrm{g} / \mathrm{mL})\end{array}$} & $\mathrm{ME}$ & $\begin{array}{c}5935.71 \\
(1315.33)\end{array}$ & $\begin{array}{c}5252.76 \\
(1084.06)\end{array}$ & $\begin{array}{c}4685.42 \\
(1043.31)\end{array}$ & $\begin{array}{l}4512.34 \\
(794.61)\end{array}$ & Time & 1.191 & 0.323 \\
\hline & BCAA & $\begin{array}{l}5139.04 \\
(909.07)\end{array}$ & $\begin{array}{c}4069.64 \\
(1009.10)\end{array}$ & $\begin{array}{c}5416.47 \\
(1539.50)\end{array}$ & $\begin{array}{c}5575.80 \\
(1181.43)\end{array}$ & Time ${ }^{*}$ group & 2.010 & 0.059 \\
\hline & CG & $\begin{array}{l}4623.56 \\
(699.03)\end{array}$ & $\begin{array}{c}4593.56 \\
(1310.34)\end{array}$ & $\begin{array}{l}4655.42 \\
(815.10)\end{array}$ & $\begin{array}{l}4327.39 \\
(863.95)\end{array}$ & & & \\
\hline \multirow{4}{*}{$\begin{array}{l}\text { Albumin } \\
(\mathrm{g} / \mathrm{dL})\end{array}$} & $\mathrm{ME}+\mathrm{BCAA}$ & $3.60(0.39)$ & $3.63(0.61)$ & $3.82(0.54)$ & $3.75(0.63)$ & & & \\
\hline & ME & $3.73(0.61)$ & $4.12(0.74)$ & $3.57(0.43)$ & $4.13(0.22)$ & Time & 3.841 & 0.013 \\
\hline & BCAA & $3.77(0.39)$ & $3.61(0.40)$ & $1.56(2.15)$ & $2.83(1.60)$ & Time ${ }^{*}$ group & 1.446 & 0.185 \\
\hline & CG & $3.75(0.72)$ & $3.60(0.35)$ & $2.59(1.85)$ & $2.96(1.69)$ & & & \\
\hline \multirow{4}{*}{$\begin{array}{l}\text { 5TSS test } \\
\text { (s) }\end{array}$} & $\mathrm{ME}+\mathrm{BCAA}$ & $21.87(3.64)$ & $18.71(3.59)$ & $20.66(4.98)$ & $17.54(4.4)$ & & & \\
\hline & $\mathrm{ME}$ & $26.69(12.98)$ & $28.02(11.28)$ & $26.08(10.46)$ & $27.56(12.24)$ & Time & 0.165 & 0.841 \\
\hline & BCAA & $36.54(14.14)$ & 36.24 (13.39) & 36.74 (11.89) & $35.76(17.28)$ & Time ${ }^{*}$ group & 0.436 & 0.846 \\
\hline & CG & $24.58(8.99)$ & $24.76(9.0)$ & $23.66(9.30)$ & $25.17(9.75)$ & & & \\
\hline \multirow{4}{*}{$\begin{array}{l}\text { Physical Frailty } \\
\text { (index) }\end{array}$} & $\mathrm{ME}+\mathrm{BCAA}$ & $2.00(0.53)$ & $1.50(0.53)$ & $2.12(0.99)$ & $2.00(0.53)$ & & & \\
\hline & ME & $2.71(1.1)$ & $2.57(1.13)$ & $2.14(0.69)$ & $2.00(0.81)$ & Time & 2.702 & 0.05 \\
\hline & BCAA & $3.00(0.57)$ & $2.14(0.37)$ & $2.28(1.25)$ & $2.71(0.48)$ & Time ${ }^{*}$ group & 3.799 & 0.00 \\
\hline & CG & $2.16(0.71)$ & $2.25(0.75)$ & $2.66(0.49)$ & $3.16(0.71)$ & & & \\
\hline \multirow{4}{*}{$\begin{array}{c}\text { MMSE } \\
\text { (0-30 points) }\end{array}$} & $\mathrm{ME}+\mathrm{BCAA}$ & $26.00(3.11)$ & $26.37(2.44)$ & $26.00(2.87)$ & $24.37(3.58)$ & & & \\
\hline & ME & $21.00(3.78)$ & $22.42(2.99)$ & $21.00(4.65)$ & $20.00(3.91)$ & Time & 4.262 & 0.13 \\
\hline & BCAA & $20.85(2.79)$ & $19.42(4.07)$ & $20.71(4.02)$ & $19.57(3.64)$ & Time ${ }^{*}$ group & 1.214 & 0.305 \\
\hline & CG & $21.69(2.89)$ & $23.92(3.47)$ & $23.23(3.83)$ & $21.76(2.94)$ & & & \\
\hline
\end{tabular}

Notes: $\mathrm{M} \pm$ SD: Mean (standard and deviation); ME: Multicomponent exercise; BCAA: Branched-chain amino acids; IL: Interleukin; TNF- $\alpha$ : Tumor Necrosis Factor-alpha; MPO: Myeloperoxidase; MMSE: Mini Mental State Exam; 5TSS test: Five-Times-Sit-to-Stand-Test; T1 to T2 (elastic-band exercise, 16 weeks, 8 weeks), T2 to T3 (wash-out), T3 to T4 (multicomponent exercise, 16 weeks). ${ }^{*}$ time versus group interactions. Statistically significant differences are denoted in bold.

\subsection{Cognitive Assessment}

The results obtained in the cognitive profile (Table 4), show that, at baseline (T1), $65.7 \%$ of the participants $(n=23)$ scored below the 24 -point threshold in the MMSE test, indicating that a significant fraction of participants was within the mild/moderate cognitive impairment classification. In addition, at the same time-point (T1), significant differences were found for the cognitive score between the ME + BCAAs group and the other groups $(p<0.05)$. An effect of time $(\mathrm{F}(\mathrm{df}: 3,93)=4.262, p=0.007)$, but not interaction (time vs. group, $p=0.296$ ), was observed for the MMSE results. The cognitive MMSE scores increased in the control group between T1 and T2 but decreased subsequently in T3 and T4 $(p=0.008)$. No significant alterations were observed in the other groups. At baseline, $45.7 \%$ of the participants were classified as frail and $54.3 \%$ as pre-frail.

\section{Discussion}

This study evaluated the effects of exercise and BCAAs on biomarkers of immunity, total albumin, and the cognitive profile of institutionalized older persons. The main findings were that ME showed more proemint result, particullary with BCAA in the improve cogni- 
tive profile and muscle strength-related albumin levels in plasma and diminish the frailty status. Moreover, exercise induced slight changes on the pro-inflammatory marker TNF- $\alpha$.

Albumin levels tend to decrease with age, and this effect seems to imply an increased risk of complications and higher rate of mortality, morbidity, and disabilities such as sarcopenia and frailty [56]. Despite the key participation of albumin on the $\mathrm{pH}$ balance and ionic homeostasis in blood, most of the free fatty acid (and some other lipids) transport in the bloodstream is also performed by serum albumin [57]. Not surprisingly, the agerelated impaired albuminemia and elevated serum anion gap are known to be associated with hypertension, low cardiorespiratory fitness, and decreased renal function, which are common morbidities of advanced aged people [58]. Therefore, interventions that aim to sustain (or even increase) albuminemia in older persons could represent an important strategy to mitigate the harmful effects of aging and its comorbidities. In this respect, some studies have already shown that BCAAs apparently increases albumin levels in older persons suffering from malnutrition [59].

Our results showed that the serum albumin levels were efficiently sustained or even augmented, in exercising participants (both $\mathrm{ME}$ and $\mathrm{ME}+\mathrm{BCAAs}$ groups) during the first 16 weeks of intervention (phase 1). However, the withdrawal of BCAAs during the washout period (phase 2) quickly decreased those albumin levels, especially in the BCAAs group. The prominent effect of exercise on albumin levels was evident since its levels in both ME and ME + BCAAs groups were fully restored after the phase 3 period (T3 to T4 time-points), whereas only partial recoveries were observed in albumin levels in the BCAAs group at the same time-point. Low serum albumin levels were shown to be the most relevant biomarkers associated with poor physical strength in the older persons [60].

It is broadly accepted that the regular practice of exercise training imposes metabolic, endocrine/physiological, immune, and cognitive adaptations that, among many benefits, can increase skeletal muscle mass and strength, thus, circumventing the deleterious effects of sarcopenia in older persons [61].

The chronic exercise-mediated adjustments on insulin/glucagon balance, thyroid, and steroid hormones, such as testosterone, cortisol, and estrogens, can also be involved in the enhancement of hepatic and protein muscle metabolism (proteolysis, proteogenesis, and protein turnover), with clear consequences on the circulating amino acid levels (e.g., glutamine and alanine), blood $\mathrm{pH}$ and electrolyte balance (hydric/ionic homeostasis), and renal functions [62].

However, it was reported that the putative effect of amino acid/protein supplementation in older women could be masked by sufficient daily protein intake, as we attested in all institutionalized participants in this study [63]. Thus, the proper mechanism behind this effect still needs to be fully understood for this special population. In fact, to our knowledge, this is the first study to show the potential of physical exercise associated or not with BCAAs supplementation to maintain serum albumin levels in older persons living in $\mathrm{RCH}$.

Contrarily to the albumin results, the monitored inflammatory markers (IL-10, TNF- $\alpha$, and MPO) did not show significant alterations over time. Apparently, we can putatively suggest, that the physical exercise intensities reached in the sessions, as well as the BCAAs supplementation effect compared to the daily protein intake in this population, were not sufficient to induce a significant impact on the inflammatory status in the participants in this study. Other interventions with older persons have been able to show a strong anti-inflammatory effect of exercise training, but it seems that these results were observed for intervention periods longer than 16 weeks [43,44].

Interestingly, even though an increase in the levels of the pro-inflammatory cytokine TNF- $\alpha$ was observed in the ME + BCAAs group from T1 to T2 and T3, this finding was accompanied by a proportional increase of the anti-inflammatory cytokine IL-10, since the TNF- $\alpha / \mathrm{IL}-10$ ratio was not different in this group over time. Moreover, at the end of the intervention, TNF- $\alpha$ levels significantly decreased in this group. In accordance with 
the literature, IL-10 is a key anti-inflammatory cytokine that acts by inhibiting systemic inflammation mediated by TNF- $\alpha$ [64].

Concomitantly, BCAAs alone did not induce alterations in both IL-10 and TNF- $\alpha$ levels. These results differ slightly from what is observed in the literature regarding this type of intervention on inflammatory status [65]. Based on the literature, there is a close interaction between the inflammatory status and aging, and in this respect, it is widely accepted that older persons, especially sedentary people, present a chronic, systemic, sterile low-grade inflammation associated with aging, a phenomenon named inflammaging [66]. It is highlighted that inflammaging plays an important role in the loss of lean mass, which leads to sarcopenia and frailty, as well as increases the risk of the development of diseases and comorbidities, such as cognitive decline, atherosclerosis, insulin resistance, etc. [67].

Despite the fact that literature defines the ability to induce an anti-inflammatory change as a hallmark of physical exercise, in general, our results did not corroborate this fact. It is paramount to mention that some factors could putatively influence the lack of significant results in the inflammatory analysis. Firstly, the occurrence of inflammaging and pathophysiological disturbances in our participants could be crucial for the response magnitude observed during the interventions here. Second, the low level of physical activity of our participants before the interventions could mitigate the benefits that would be achieved with the physical exercise sessions and, consequently, limit physiological adaptation. These factors, associated with polypharmacy, a high rate of comorbidities, and the small sample size that finished the study, may determine the lack of significant effects observed.

There is a consensus in the literature that physical exercise sessions stimulate the release of cytokines, such as IL-6, IL-10, and TNF- $\alpha$, in response to contracting skeletal muscles, which are responsible not only for tissue restoration and energy metabolism, but also for the adjustment of the systemic inflammatory status [68].As appealing as these effects are, physical exercise training also improves human antioxidant defenses as observed in several studies which may also justify the use of exercise interventions to counteract the progression of oxidative-related diseases [69].

There are solid pieces of evidence that the loss of muscle strength and power in the lower limbs, which is characterized by a decline of up to $50 \%$ in overall muscle strength from the age of 30 to 80 years $[52,53]$ is associated with an increased incidence of falls.

Particularly, physical exercise training improves body composition, muscle strength, metabolic parameters, bone health, and functionality as well as reduces the risk of mortality, chronic diseases, cognitive deterioration, falls, and depression [70]. Here, we observed that only the ME + BCAAs group presented an improved physical performance in the 5TSS test. Neither ME or BCAAs alone were sufficient to mediate improvements in lower body strength. Only the combination of exercise and supplementation did so. This result was achieved probably due to multiple factors, from physiological to cognitive positive effects that were not directly assessed by the applied methodology here. According to the literature, the 5TSS test is an important performance test that invokes physical skills and abilities that could have been particularly developed during phase 3 of this study. The phase 3 of our study included walking activities, steps, and balance exercises, which mimic the participants' regular daily life activities.

It is important to point out that strength exercise training has been proposed as one of the most effective methodologies, presenting best results in bringing back safety in per-forming the common tasks of daily life, focusing on the optimization of neuromuscular function for better benefits [71].

Multicomponent programs combine aerobic and strength exercises, including other physical skills, such as balance and flexibility [54], in order to optimize the functional capacity of frail older persons [72], as well as to maintain their independence to perform basic activities of daily living [73]. Concerning supplementation, it was reported that branched-chain amino acids, particularly L-leucine, showed significant results in inducing hypertrophy in older persons and improving their functional capacity $[58,59]$. 
Taking into account that cognitive impairment is one of the main factors that cause morbidity and high health costs worldwide [74], our results show that physical exercise training, in association or not with BCAAs, was able to maintain the cognitive scores of the participants and could have important practical applications. Considering the population enrolled here (pre-frail and frail octogenarians) and the trend for the natural decline of their cognitive functions, the maintenance of those cognitive scores by exercise is, per se, a remarkable achievement. The literature supports the positive effect of BCAAs in older persons, to improve their mood state [75], the perception of fatigue, and their performance in a mental task [76], which are abilities that were not evaluated here. Leucine is important since it activates the mammalian target of rapamycin complex 1 (mTORC1) and the downstream phosphorylation of p70S6 kinase and 4E (eIF4E)-binding protein 1 (4E-BP1) and related signaling pathways [77]. The aging muscle is less responsive to lower doses of amino acids when compared to the young muscle and may require higher quantities of protein to acutely stimulate equivalent muscle protein synthesis [78]. Nevertheless, the dose and duration of BCAAs proposed here did not affect the cognition scores in our participants.

\section{Study Limitation and Perspectives for Future Researchers}

The entire study was conducted with human octogenarians and, given the difficulty to control several influencing factors in this type of population, this study had the additional merit of causing a minimal impact on their daily routines at the residential care homes. In addition, our results here represent real-world data reflecting the reality at residential care homes. We screened participants with disabilities and comorbidities that, although expecting high rate of dropouts and low motivational issues, we could accomplish the proposed goals with a reasonable number of participants. The execution of a controlled study over 40 weeks with such a particular population also introduces other limitations. We suggest that the use of other methods of exercise training, such as the use of playful activities (dance and music sessions) might elevate the adherence of this population to the program.

\section{Conclusions}

This study showed that multicompetent exercise training, with minor effect of BCAAs, triggered alterations in the inflammatory status and physical profiles of older persons, while helping maintain cognitive levels. Taken together, the achieved results, could help increase autonomy and efficiency in the performance of daily activities. Unlike other studies, our results showed that supplementation with BCAA did not induce substantial changes in health-related parameters at older ages. It is possible that the heterogeneity and limited sample size might have limited the statistical relevance of our results. Despite a slight and transient variation over time observed in some inflammatory and cognitive parameters, it is possible that the results here were influenced by the comorbidity status of each group.

Author Contributions: A.C.-S. drafted the paper; G.E.F. worked on the methodology of the study aspects of RCT; R.N. helped with data acquisition; M.U.C. statically analyzed the data; A.M.T., A.M. and E.M. developed the study proposal, revised the manuscript critically, and suggested additional statistical analyses; A.M.T. coordinated the research study and, together with M.P.d.B. and A.L.L.B., revised the manuscript critically. All authors have read and agreed to the published version of the manuscript.

Funding: Portuguese Foundation for Science and Technology—CIDAF (UID/DTP/0413/2020). BCAA supplement provided free of cost by MyProtein ${ }^{\circledR}$, Cheshire, UK.

Institutional Review Board Statement: This study was conducted according to the guidelines of the and approved by the University of Coimbra, Faculty of Sport Sciences and Physical Education Ethical Committee (reference number: CE/FCDEFUC/00282018), https:/ / clinicaltrials.gov/ct2 /show / NCT04376463 (accessed on 5 May 2020). 
Informed Consent Statement: Informed consent was obtained from all subjects involved in the study.

Data Availability Statement: The data presented in this study are available on request from the corresponding author. Data supporting the reported results is the property of CIDAF, Faculty of Sport Sciences and Physical Education, University of Coimbra, Coimbra, Portugal.

Acknowledgments: We would like to thank the $\mathrm{RCH}$ for accepting to participate in this study. Thanks to the Pedro Alexandre Ferreira Filipe nurse for volunteering with the data collection and Ana Vieira-Pedrosa and Rafael Rodrigues for helping with the data collection. The authors would like to thank Jonatas Bussador do Amaral for his assistance in the graphical abstract. The authors M.P.B. and A.L.L.B. are fellows of the Brazilian National Council for Scientific and Technology Development (CNPq; M.P.B.: PQ-2 \#305818/2018-0; A.L.L.B.: PQ-2 \#307674/2017-7, Brazil).

Conflicts of Interest: The authors declare that there are no conflict of interest.

\section{References}

1. Aiello, A.; Farzaneh, F.; Candore, G.; Caruso, C.; Davinelli, S.; Gambino, C.M.; Ligotti, M.E.; Zareian, N.; Accardi, G. Immunosenescence and its hallmarks: How to oppose aging strategically? A review of potential options for therapeutic intervention. Front. Immunol. 2019, 10, 1-19. [CrossRef]

2. Duggal, N.A.; Niemiro, G.; Harridge, S.D.; Simpson, R.J.; Lord, J.M. Can physical activity ameliorate immunosenescence and thereby reduce age-related multi-morbidity? Nat. Rev. Immunol. 2019, 19, 563-572. [CrossRef] [PubMed]

3. Amirato, G.R.; Borges, J.O.; Marques, D.L.; Santos, J.M.B.; Santos, C.A.F.; Andrade, M.S.; Furtado, G.E.; Rossi, M.; Luis, L.N.; Zambonatto, R.F.; et al. L-glutamine supplementation enhances strength and power of knee muscles and improves glycemia control and plasma redox balance in exercising elderly women. Nutrients 2021, 13, 1025. [CrossRef]

4. Chodzko-Zajko, W.; Schwingel, A. Successful Aging: The Role of Physical Activity. Am. J. Lifestyle Med. 2008, 3, 20-28. [CrossRef]

5. Bauman, A.; Merom, D.; Bull, F.C.; Buchner, D.M.; Fiatarone Singh, M.A. Updating the Evidence for Physical Activity: Summative Reviews of the Epidemiological Evidence, Prevalence, and Interventions to Promote "active Aging". Gerontologist 2016, 56, S268-S280. [CrossRef]

6. Sherrington, C.; Fairhall, N.; Kirkham, C.; Clemson, L.; Howard, K.; Vogler, C.; Close, J.C.; Moseley, A.M.; Cameron, I.D.; Mak, J.; et al. Exercise and fall prevention self-management to reduce mobility-related disability and falls after fall-related lower limb fracture in older people: Protocol for the RESTORE (Recovery Exercises and Stepping on after Fracture) randomised controlled trial. BMC Geriatr. 2016, 16, 34. [CrossRef] [PubMed]

7. Cavalcante, P.A.M.; Doro, M.R.; Suzuki, F.S.; Rica, R.L.; Serra, A.J.; Pontes Junior, F.L.; Evangelista, A.L.; Figueira Junior, A.J.; Baker, J.S.; Bocalini, D.S. Functional Fitness and Self-Reported Quality of Life of Older Women Diagnosed with Knee Osteoarthrosis: A Cross-Sectional Case Control Study. J. Aging Res. 2015, 2015, 841985. [CrossRef]

8. Covinsky, K.E.; Eng, C.; Lui, L.-Y.; Sands, L.P.; Yaffe, K. The last 2 years of life: Functional trajectories of frail older people. J. Am. Geriatr. Soc. 2003, 51, 492-498. [CrossRef]

9. Fried, L.P.; Tangen, C.M.; Walston, J.; Newman, A.B.; Hirsch, C.; Gottdiener, J.; Seeman, T.; Tracy, R.; Kop, W.J.; Burke, G.; et al. Frailty in Older Adults: Evidence for a Phenotype. J. Gerontol. Ser. A Biol. Sci. Med. Sci. 2001, 56, M146-M157. [CrossRef]

10. Rodakowski, J.; Saghafi, E.S.; Butters, M.A.; Skidmore, E.R. Nonpharmacological Interventions in Adults with MCI and Early dementia. Mol. Asp. Med. 2015, 38-53. [CrossRef]

11. Ruan, Q.; Yu, Z.; Chen, M.; Bao, Z.; Li, J.; He, W. Cognitive frailty, a novel target for the prevention of elderly dependency. Ageing Res. Rev. 2015, 20,1-10. [CrossRef]

12. Higueras-Fresnillo, S.; Cabanas-Sánchez, V.; Lopez-Garcia, E.; Esteban-Cornejo, I.; Banegas, J.R.; Sadarangani, K.P.; RodríguezArtalejo, F.; Martinez-Gomez, D. Physical Activity and Association Between Frailty and All-Cause and Cardiovascular Mortality in Older Adults: Population-Based Prospective Cohort Study. J. Am. Geriatr. Soc. 2018, 66, 2097-2103. [CrossRef]

13. Gleeson, M.; Bishop, N.C.; Stensel, D.J.; Lindley, M.R.; Mastana, S.S.; Nimmo, M.A. The anti-inflammatory effects of exercise: Mechanisms and implications for the prevention and treatment of disease. Nat. Rev. Immunol. 2011, 11, 607-615. [CrossRef]

14. Tarazona-Santabalbina, F.J.; Gómez-Cabrera, M.C.; Pérez-Ros, P.; Martínez-Arnau, F.M.; Cabo, H.; Tsaparas, K.; Salvador-Pascual, A.; Rodriguez-Mañas, L.; Viña, J. A Multicomponent Exercise Intervention that Reverses Frailty and Improves Cognition, Emotion, and Social Networking in the Community-Dwelling Frail Elderly: A Randomized Clinical Trial. J. Am. Med. Dir. Assoc. 2016, 17, 426-433. [CrossRef]

15. Theou, O.; Stathokostas, L.; Roland, K.P.; Jakobi, J.M.; Patterson, C.; Vandervoort, A.A.; Jones, G.R. The effectiveness of exercise interventions for the management of frailty: A systematic review. J. Aging Res. 2011, 2011, 569194. [CrossRef]

16. Woods, J.A.; Keylock, K.T.; Lowder, T.; Vieira, V.J.; Zelkovich, W.; Dumich, S.; Colantuano, K.; Lyons, K.; Leifheit, K.; Cook, M.; et al. Cardiovascular exercise training extends influenza vaccine seroprotection in sedentary older adults: The immune function intervention trial. J. Am. Geriatr. Soc. 2009, 57, 2183-2191. [CrossRef]

17. Paixão, V.; Almeida, E.B.; Amaral, J.B.; Roseira, T.; Monteiro, F.R.; Foster, R.; Sperandio, A.; Rossi, M.; Amirato, G.R.; Santos, C.A.F.; et al. Elderly Subjects Supplemented with L-Glutamine Shows an Improvement of Mucosal Immunity in the Upper Airways in Response to Influenza Virus Vaccination. Vaccines 2021, 9, 107. [CrossRef] 
18. Abizanda, P.; Sinclair, A.; Barcons, N.; Lizán, L.; Rodríguez-Mañas, L. Costs of Malnutrition in Institutionalized and CommunityDwelling Older Adults: A Systematic Review. J. Am. Med. Dir. Assoc. 2016, 17, 17-23. [CrossRef]

19. Goates, S.; Du, K.; Braunschweig, C.A.; Arensberg, M.B. Economic burden of disease-associated malnutrition at the state level. PLoS ONE 2016, 11, 1-15. [CrossRef]

20. Artaza-Artabe, I.; Sáez-López, P.; Sánchez-Hernández, N.; Fernández-Gutierrez, N.; Malafarina, V. The relationship between nutrition and frailty: Effects of protein intake, nutritional supplementation, vitamin D and exercise on muscle metabolism in the elderly. A systematic review. Maturitas 2016, 93, 89-99. [CrossRef] [PubMed]

21. Ikeda, T.; Aizawa, J.; Nagasawa, H.; Gomi, I.; Kugota, H.; Nanjo, K.; Jinno, T.; Masuda, T.; Morita, S. Effects and feasibility of exercise therapy combined with branched-chain amino acid supplementation on muscle strengthening in frail and pre-frail elderly people requiring long-term care: A crossover trial. Appl. Physiol. Nutr. Metab. 2016, 41, 438-445. [CrossRef] [PubMed]

22. Ikeda, T.; Matsunaga, Y.; Kanbara, M.; Kamono, A.; Masuda, T.; Watanabe, M.; Nakanishi, R.; Jinno, T. Effect of exercise therapy combined with branched-chain amino acid supplementation on muscle strength in elderly women after total hip arthroplasty: A randomized controlled trial. Asia Pac. J. Clin. Nutr. 2019, 28, 720-726. [CrossRef] [PubMed]

23. Giannopoulou, I.; Fernhall, B.; Carhart, R.; Weinstock, R.S.; Baynard, T.; Figueroa, A.; Kanaley, J.A. Effects of diet and/or exercise on the adipocytokine and inflammatory cytokine levels of postmenopausal women with type 2 diabetes. Metabolism 2005, 54, 866-875. [CrossRef]

24. Loria, V.; Dato, I.; Graziani, F.; Biasucci, L.M. Myeloperoxidase: A new biomarker of inflammation in ischemic heart disease and acute coronary syndromes. Mediat. Inflamm. 2008, 2008. [CrossRef] [PubMed]

25. Giovannini, S.; Onder, G.; Leeuwenburgh, C.; Carter, C.; Marzetti, E.; Russo, A.; Capoluongo, E.; Pahor, M.; Bernabei, R.; Landi, F. Myeloperoxidase levels and mortality in frail community-living elderly individuals. J. Gerontol. Ser. A Biol. Sci. Med. Sci. 2010, 65 A, 369-376. [CrossRef]

26. Chupel, M.U.; Minuzzi, L.G.; Furtado, G.E.; Santos, M.L.; Ferreira, J.P.; Filaire, E.; Teixeira, A.M. Taurine supplementation reduces myeloperoxidase and matrix-Metalloproteinase-9 levels and improves the effects of exercise in cognition and physical fitness in older women. Amino Acids 2021, 1-13. [CrossRef]

27. Alcorta, M.D.; Alvarez, P.C.; Cabetas, R.N.; Martín, M.A.; Valero, M.; Candela, C.G. The importance of serum albumin determination method to classify patients based on nutritional status. Clin. Nutr. ESPEN 2018, 25, 110-113. [CrossRef]

28. Abizanda, P.; López, M.D.; García, V.P.; de Estrella, J.D.; da Silva, G.Á.; Vilardell, N.B.; Torres, K.A. Effects of an Oral Nutritional Supplementation Plus Physical Exercise Intervention on the Physical Function, Nutritional Status, and Quality of Life in Frail Institutionalized Older Adults: The ACTIVNES Study. J. Am. Med. Dir. Assoc. 2015, 1, 439.e9-439.e16. [CrossRef]

29. Guralnik, J.M.; Ferrucci, L.; Simonsick, E.M.; Salive, M.E.; Wallace, R.B. A short physical performance battery Assessing Lower Extremety Function: Association with self reported disability and prediction of mortality and nursing home admission. J. Gerontol. 1994, 49, M85-M94. [CrossRef]

30. Begg, M.; Eastwood, E.; Horton, R.; Moher, M.; Ingram, O.; Pitkin, R.; Drummond, R.; Schulz, K.; Simel, D.; Stroup, D. Improving the Quality of Reporting of Randomized Controlled Trials The CONSORT Statement. JAMA 1996, J276, 637-639. [CrossRef]

31. Gonçalves, B.; Fagulha, T.; Ferreira, A.; Reis, N. Depressive symptoms and pain complaints as predictors of later development of depression in Portuguese middle-aged women. Health Care Women Int. 2014, 35, 1228-1244. [CrossRef] [PubMed]

32. Syddall, H.; Cooper, C.; Martin, F.; Briggs, R.; Aihie Sayer, A. Is grip strength a useful single marker of frailty? Age Ageing 2003, 32, 650-656. [CrossRef]

33. Campaniço Validade Simultânea do Questionário. Internacional de Actividade Física Através da Medição Objectiva da Actividade Física por Actigrafia Proporcional. 2016. Available online: http://hdl.handle.net/10400.5/11866 (accessed on 1 March 2021).

34. Torres, D.; Oliveira, A.; Severo, M.; Alarcão, V.; Guiomar, S.; Mota, J.; Teixeira, P.; Rodrigues, S.; Vilela, S.; Oliveira, L.; et al. Inquérito Alimentar Nacional e de Atividade Física. Inq. Aliment. Nac. Ativ. Fís. IAN-AF 2015-2016 2016, 53, 1689-1699.

35. Goios, A. Pesos e Porções de Alimentos (2a Edição). In Pesos e Porções de Alimentos (2 ${ }^{a}$ Edição); U. Porto Press: Porto, Portugal, 2016; ISBN 9789897461033.

36. INSA. Tabela da Composição de Alimentos. 2006. Available online: http:/ / www2.insa.pt/sites/INSA/Portugues/AreasCientificas / AlimentNutricao/AplicacoesOnline/TabelaAlimentos/Paginas/TabelaAlimentos.aspx (accessed on 2 March 2021).

37. Vellas, B.; Guigoz, Y.; Garry, P.J.; Nourhashemi, F.; Bennahum, D.; Lauque, S.; Albarede, J.L.; Vellas, B. The Mini Nutritional Assessment (MNA) for grading the nutritional state of elderly patients: Presentation of the MNA, history and validation. Nestle Nutr. Workshop Ser. Clin. Perform. Programme 1999, 1, 3-11. [CrossRef]

38. Loureiro, M.H.V.S. Validação do “Mini-Nutricional Assessement" em Idosos. Available online: https://estudogeral.uc.pt/ handle/10316/10439 (accessed on 1 March 2021).

39. Charlson, M.; Szatrowski, T.P.; Peterson, J.; Gold, J. Validation of a combined comorbidity index. J. Clin. Epidemiol. 1994, 47, 1245-1251. [CrossRef]

40. Lohman, T.G.; Roche, A.F.; Martorell, R. Lohman Anthropometric Standardization Reference Manual; Human Kinetics Books: Champaign, IL, USA, 1992.

41. Morgado, J.; Rocha, C.S.; Maruta, C.; Guerreiro, M.; Martins, I.P. Novos valores normativos do mini-mental state examination. Sinapse 2009, 9, 2009.

42. Folstein Mini-mental State. A grading the cognitive state of patiens for the clinician. J. Psychiatr Res. 1975, 12, 189-198. [CrossRef] 
43. Ispoglou, T.; White, H.; Preston, T.; McElhone, S.; McKenna, J.; Hind, K. Double-blind, placebo-controlled pilot trial of L-Leucineenriched amino-acid mixtures on body composition and physical performance in men and women aged 65-75 years. Eur. J. Clin. Nutr. 2016, 70, 182-188. [CrossRef]

44. Negro Perna, S.; Spadaccini, D.; Castelli, L.; Calanni, L.; Barbero, M.; Cescon, C.; Rondanelli, M. D’antonaEffects of 12 Weeks of Essential Amino Acids (EAA)-Based Multi-Ingredient Nutritional Supplementation on Muscle Mass, Muscle Strength, Muscle Power and Fatigue in Healthy Elderly Subjects: A Randomized Controlled Double-Blind Study. J. Nutr. Health Aging 2019, 23, 414-424. [CrossRef]

45. Honka, X.M.J.; Bucci, M.; Andersson, J.; Huovinen, V.; Guzzardi, M.A.; Sandboge, S.; Savisto, N.; Salonen, M.K.; Badeau, R.M.; Parkkola, R.; et al. Resistance training enhances insulin suppression of endogenous glucose production in elderly women. J. Appl. Physiol. 2016, 120, 633-639. [CrossRef] [PubMed]

46. Solis, M.Y.; Cooper, S.; Hobson, R.M.; Artioli, G.G.; Otaduy, M.C.; Roschel, H.; Robertson, J.; Martin, D.; Painelli, V.S.; Harris, R.C.; et al. Effects of beta-alanine supplementation on brain homocarnosine/carnosine signal and cognitive function: An exploratory study. PLoS ONE 2015, 10, 1-16. [CrossRef] [PubMed]

47. Nelson, M.E.; Rejeski, W.J.; Blair, S.N.; Duncan, P.W.; Judge, J.O.; King, A.C.; Macera, C.A.; Castaneda-Sceppa, C. Physical activity and public health in older adults: Recommendation from the American College of Sports Medicine and the American Heart Association. Med. Sci. Sports Exerc. 2007, 39, 1435-1445. [CrossRef] [PubMed]

48. de Souto Barreto, P.; Morley, J.E.; Chodzko-Zajko, W.; Pitkala, K.H.; Weening-Djiksterhuis, E.; Rodriguez-Mañas, L.; Barbagallo, M.; Rosendahl, E.; Sinclair, A.; Landi, F.; et al. Recommendations on Physical Activity and Exercise for Older Adults Living in Long-Term Care Facilities: A Taskforce Report. J. Am. Med. Dir. Assoc. 2016, 17, 381-392. [CrossRef] [PubMed]

49. Colado, J.C.; Pedrosa, F.M.; Juesas, A.; Gargallo, P.; Carrasco, J.J.; Flandez, J.; Chupel, M.U.; Teixeira, A.M.; Naclerio, F. Concurrent validation of the OMNI-Resistance Exercise Scale of perceived exertion with elastic bands in the elderly. Exp. Gerontol. 2018, 103, 11-16. [CrossRef]

50. Tanaka, H.; Monahan, K.D.; Seals, D.R. Age-predicted maximal heart rate revisited. J. Am. Coll. Cardiol. 2001, 37, 153-156. [CrossRef]

51. Borg, G.A. Psychophysical Bases of Perception Exertion. Med. Sci. Sports Exerc. 1982, 14, 377-381. [CrossRef]

52. Sakugawa, R.L.; Moura, B.M.; Orssatto, L.B.d.R.; Bezerra, E.d.S.; Cadore, E.L.; Diefenthaeler, F. Effects of resistance training, detraining, and retraining on strength and functional capacity in elderly. Aging Clin. Exp. Res. 2019, 31, 31-39. [CrossRef]

53. Furtado, G.E.; Carvalho, H.M.; Loureiro, M.; Patrício, M.; Uba-Chupel, M.; Colado, J.C.J.C.; Hogervorst, E.; Ferreira, J.P.J.P.; Teixeira, A.M. Chair-based exercise programs in institutionalized older women: Salivary steroid hormones, disabilities and frailty changes. Exp. Gerontol. 2020, 130, 110790. [CrossRef]

54. Baker, M.K.; Atlantis, E.; Fiatarone Singh, M.A. Multi-modal exercise programs for older adults. Age Ageing 2007, 36, 375-381. [CrossRef]

55. Rivera-Torres, S.; Fahey, T.D.; Rivera, M.A. Adherence to Exercise Programs in Older Adults: Informative Report. Gerontol. Geriatr Med. 2019, 5, 233372141882360. [CrossRef]

56. Vandewoude, M.F.J.; Alish, C.J.; Sauer, A.C.; Hegazi, R.A. Malnutrition-sarcopenia syndrome: Is this the future of nutrition screening and assessment for older adults? J. Aging Res. 2012, 2012. [CrossRef] [PubMed]

57. Pilgeram, L. Control of fibrinogen biosynthesis: Role of the FFA/Albumin ratio. Cardiovasc. Eng. 2010, 10, 78-83. [CrossRef]

58. Ahn, S.Y.; Ryu, J.; Baek, S.H.; Han, J.W.; Lee, J.H.; Ahn, S.; Kim, K.I.; Chin, H.J.; Na, K.Y.; Chae, D.W.; et al. Serum anion gap is predictive of mortality in an elderly population. Exp. Gerontol. 2014, 50, 122-127. [CrossRef]

59. Hiroshige, K.; Sonta, T.; Suda, T.; Kanegae, K.; Ohtani, A. Oral supplementation of branched-chain amino acid improves nutritional status in elderly patients on chronic haemodialysis. Nephrol. Dial. Transplant. 2001, 16, 1856-1862. [CrossRef]

60. Barbalho, S.M.; Flato, U.A.P.; Tofano, R.J.; Goulart, R.d.A.; Guiguer, E.L.; Detregiachi, C.R.P.; Buchaim, D.V.; Araújo, A.C.; Buchain, R.L.; Reina, F.T.R.; et al. Physical exercise and myokines: Relationships with sarcopenia and cardiovascular complications. Int. J. Mol. Sci. 2020, 21, 3607. [CrossRef]

61. Pedrero-Chamizo, R.; Albers, U.; Palacios, G.; Pietrzik, K.; Meléndez, A.; González-Gross, M. Health risk, functional markers and cognitive status in institutionalized older adults: A longitudinal study. Int. J. Environ. Res. Public Health 2020, 17, 7303. [CrossRef] [PubMed]

62. Starling, R.D.; Ades, P.A.; Poehlman, E.T. Physical activity, protein intake, and appendicular skeletal muscle mass in older men. Am. J. Clin. Nutr. 1999, 70, 91-96. [CrossRef]

63. Zhu, K.; Kerr, D.A.; Meng, X.; Devine, A.; Solah, V.; Binns, C.W.; Prince, R.L. Two-year whey protein supplementation did not enhance muscle mass and physical function in well-nourished healthy older postmenopausal women. J. Nutr. 2015, 145, 2520-2526. [CrossRef]

64. Saraiva, M.; O'Garra, A. The regulation of IL-10 production by immune cells. Nat. Rev. Immunol. 2010, 10, 170-181. [CrossRef] [PubMed]

65. Ohno, T.; Tanaka, Y.; Sugauchi, F.; Orito, E.; Hasegawa, I.; Nukaya, H.; Kato, A.; Matunaga, S.; Endo, M.; Tanaka, Y.; et al. Suppressive effect of oral administration of branched-chain amino acid granules on oxidative stress and inflammation in HCV-positive patients with liver cirrhosis. Hepatol. Res. 2008, 38, 683-688. [CrossRef] 
66. Franceschi, C.; Capri, M.; Monti, D.; Giunta, S.; Olivieri, F.; Sevini, F.; Panourgia, M.P.; Invidia, L.; Celani, L.; Scurti, M.; et al. Inflammaging and anti-inflammaging: A systemic perspective on aging and longevity emerged from studies in humans. Mech. Ageing Dev. 2007, 128, 92-105. [CrossRef] [PubMed]

67. Liu, Y.Z.; Wang, Y.X.; Jiang, C.L. Inflammation: The common pathway of stress-related diseases. Front. Hum. Neurosci. 2017, 11, 1-11. [CrossRef]

68. Pedersen, B.K.; Febbraio, M.A. Muscles, exercise and obesity: Skeletal muscle as a secretory organ. Nat. Rev. Endocrinol. 2012, 8, 457-465. [CrossRef] [PubMed]

69. Simioni, C.; Zauli, G.; Martelli, A.; Vitale, M.; Sacchetti, G.; Gonelli, A.; Neri, L. Oxidative stress: Role of physical exercise and antioxidant nutraceuticals in adulthood and aging. Oncotarget 2018, 9, 17181-17198. [CrossRef] [PubMed]

70. Beard, J.R.; Officer, A.M.; Cassels, A.K. WHO World Report on Ageing And HeAltH. Gerontologist 2016, 56, S163-S166. [CrossRef]

71. Cadore, E.L.; Casas-Herrero, A.; Zambom-Ferraresi, F.; Idoate, F.; Millor, N.; Gómez, M.; Rodriguez-Mañas, L.; Izquierdo, M. Multicomponent exercises including muscle power training enhance muscle mass, power output, and functional outcomes in institutionalized frail nonagenarians. Age (Omaha) 2014, 36, 773-785. [CrossRef]

72. Villareal, D.T.; Smith, G.I.; Sinacore, D.R.; Shah, K.; Mittendorfer, B. Regular Multicomponent Exercise Increases Physical Fitness and Muscle Protein Anabolism in Frail, Obese, Older Adults. Obesity 2011, 19, 312-318. [CrossRef]

73. Casas-Herrero, A.; Anton-Rodrigo, I.; Zambom-Ferraresi, F.; Sáez De Asteasu, M.L.; Martinez-Velilla, N.; Elexpuru-Estomba, J.; Marin-Epelde, I.; Ramon-Espinoza, F.; Petidier-Torregrosa, R.; Sanchez-Sanchez, J.L.; et al. Effect of a multicomponent exercise programme (VIVIFRAIL) on functional capacity in frail community elders with cognitive decline: Study protocol for a randomized multicentre control trial. Trials 2019, 20,1-12. [CrossRef]

74. Alzheimer's Association. 2020 Alzheimer's disease facts and figures. Alzheimer's Dement. 2020, 16, 391-460. [CrossRef]

75. Gariballa, S.; Forster, S. Effects of dietary supplements on depressive symptoms in older patients: A randomised double-blind placebo-controlled trial. Clin. Nutr. 2007, 26, 545-551. [CrossRef]

76. Fernstrom, J.D. Large neutral amino acids: Dietary effects on brain neurochemistry and function. Amino Acids 2013, 45, 419-430. [CrossRef] [PubMed]

77. Neishabouri, H.; Hutson, S.; Davoodi, J. Chronic activation of mTOR complex 1 by branched chain amino acids and organ hypertrophy. Amino Acids 2015, 47, 1167-1182. [CrossRef] [PubMed]

78. Ko Wu, S.; Wang, S.; Chang, Y.; Chang, C.; Kuan, T.; Chuang, H.; Chang, C.; Chou, W.; Wu, C. Effects of enriched branched-chain amino acid supplementation on sarcopenia. Aging (Albany N. Y.) 2020, 12, 15091-15103. [CrossRef] 